\title{
Komorbiditas anak gangguan spektrum autisme
}

\author{
${ }^{1}$ Scriven Y. Warouw \\ ${ }^{2}$ Christoffel Elim \\ ${ }^{2}$ Herdy Munayang \\ ${ }^{2}$ Neni Ekawardani
}

\author{
${ }^{1}$ Kandidat skripsi Fakultas Kedokteran Universitas Sam Ratulangi Manado \\ ${ }^{2}$ Bagian Psikiatri Fakultas Kedokteran Universitas Sam Ratulangi Manado \\ Email: warouwyosia@gmail.com
}

\begin{abstract}
Autism spectrum disorder is a developmental disruption. Its early condition is characterized by delay and deviance in the development of social, communication, and other skills. Someone who has been diagnosed with autism spectrum disorder is easily to encounter other health problems which occur simultaneously, the comorbidity. Comorbidities that usually occur in children with autism spectrum disorder are mental disorders and physical diseases. This study was aimed to identify the comorbidities of children with autism spectrum disorder at autism schools, exceptional schools and disabled children therapy sites in Manado and Tomohon. This was a quantitative study with a crosssectional design. The results showed that there were 31 parents of children with autism spectrum disorder as respondents. There were 30 children (96.77\%) that had comorbidities. Of the 30 children with comorbidities, 7 children had generalized anxiety disorder (22.6\%), 9 children had specific phobias (29\%), 6 children had bipolar disorders $(25.8 \%), 7$ children had ADHD (22.6\%), 22 children had allergic diseases (71\%), 23 children had gastrointestinal disorders (74.2\%), and 4 children had epilepsy (12.9\%). Conclusion: In this study, most children with autism spectrum disorder had comorbidities and gastrointestinal disorder was the most frequent comorbidity.
\end{abstract}

Keywords: comorbidity, children, autism spectrum disorder.

\begin{abstract}
Abstrak: Gangguan spektrum autisme adalah suatu gangguan perkembangan yang mana kondisi awalnya ditandai dengan keterlambatan dan penyimpangan dalam perkembangan sosial, komunikasi dan keterampilan lainnya. Orang yang didiagnosis dengan gangguan spektrum autisme sangat rentan mengalami masalah kesehatan lain yang terjadi secara bersamaan atau dikenal dengan istilah komorbiditas. Komorbiditas yang sering muncul pada anak gangguan spektrum autisme berupa gangguan mental dan penyakit fisik. Penelitian ini bertujuan untuk mengetahui komorbiditas pada anak gangguan spektrum autisme di sekolah khusus autisme, sekolah luar biasa dan tempat terapi anak berkebutuhan khusus di Kota Manado dan Tomohon. Jenis penelitian ialah kuantitatif dengan desain potong lintang terhadap 31 responden yaitu orangtua yang mempunyai anak gangguan spektrum autisme. Dari 31 responden ini didapatkan 30 anak gangguan spektrum autisme (96,77\%) mengalami komorbiditas. Dari 30 anak gangguan spektrum autisme yang mengalami komorbiditas didapatkan 7 anak mengalami gangguan cemas menyeluruh (22,6\%), 9 anak mengalami fobia spesifik (29\%), 6 anak mengalami gangguan obsesif kompulsif $(19,4 \%), 5$ anak mengalami gangguan depresif mayor $(16,1 \%), 8$ anak mengalami gangguan bipolar $(25,8), 7$ anak mengalami GPPH (22,6\%), 22 anak mengalami alergi (71\%), 23 anak mengalami gangguan gastrointestinal $(74,2 \%)$, dan 4 anak mengalami epilepsi (12,9\%). Simpulan: Hampir semua anak gangguan spektrum autisme mengalami komorbiditas dan gangguan gastrointestinal merupakan komorbiditas yang paling sering ditemukan.
\end{abstract}

Kata kunci: komorbiditas, anak, gangguan spektrum autisme. 
Gangguan perkembangan pervasif atau gangguan spektrum autisme atau lebih dikenal dengan autisme merupakan suatu masalah kesehatan tubuh baik secara fisik, mental maupun sosial. Setiap orang tua menginginkan anaknya dapat beraktifitas dengan baik, tetapi anak dengan autisme memiliki beberapa masalah yang dapat memperburuk kualitas hidupnya. Selain berdampak buruk bagi penyandang autisme, gangguan tersebut juga sangat merugikan orang-orang terdekatnya. ${ }^{1}$

Autisme merupakan suatu gangguan perkembangan. Belum diketahui secara pasti penyebab dari autisme, tetapi genetik, lingkungan dan faktor imunologi mungkin berperan dalam perjalanan dari autisme. ${ }^{1,2}$

United Nations Education Scientific and Cultural Organization (UNESCO) mencatat terdapat 35 juta orang penyandang autisme di dunia pada tahun 2011. Ini berarti rata-rata 6 dari 1000 orang di dunia menderita autisme. Penelitian Centers of Disease Control and Prevention (CDC) Amerika Serikat pada tahun 2008 menyatakan bahwa perbandingan anak yang terdiagnosis autisme adalah 1:80, kemudian hingga tahun 2013 CDC menyebutkan prevalensi penyandang autisme di Amerika Serikat menjadi 1:50, ini berarti angka kejadian anak autisme meningkat. Pemerintah Indonesia sendiri belakangan ini belum melakukan survei terbaru mengenai jumlah penyandang autisme sehingga jumlah pasti penyandang autisme di Indonesia belum pasti. Menteri kesehatan Siti Fadila Supari dalam pembukaan rangkaian expo peduli autisme yang diselenggarakan tahun 2008 lalu mengatakan, jumlah penderita autisme di Indonesia pada tahun 2004 tercatat sebanyak 475 ribu penderita. Di Sulawesi Utara khususnya di Manado belum mempunyai data mengenai jumlah anak autisme karena belum ada survei dan penelitian yang dilakukan mengenai prevalensi anak autisme. ${ }^{3-5}$

Anak yang didiagnosis dengan autisme sangat rentan mengalami masalah kesehatan lain yang terjadi secara bersamaan atau dikenal dengan istilah komorbiditas. Komorbiditas merupakan suatu kondisi terjadinya dua atau lebih gangguan pada suatu individu dan dapat memperberat kondisi yang ada. Komorbiditas telah menjadi topik yang menarik dan mendapat banyak perhatian dalam literatur psikopatologi anak. Adapun komorbiditas yang sering muncul pada autisme berupa gangguan mental dan penyakit fisik. Gangguan mental yang sering muncul seperti cemas, fobia spesifik, obsesif kompulsif, depresi, gangguan bipolar, dan gangguan pemusatan perhatian. Sedangkan penyakit fisik yang sering timbul seperti alergi, gangguan gastrointestinal dan epilepsi.

Banyak anak-anak yang didiagnosis dengan autisme memiliki komorbiditas. CDC telah melaporkan bahwa beberapa masalah kesehatan diantaranya berbagai gangguan mental dan penyakit fisik meningkat secara signifikan pada beberapa anak dengan autisme dibandingkan dengan populasi normal dan gangguan perkembangan lainnya. Menurut penelitian dalam skala besar yang dilakukan Croen dan kawan-kawan pada tahun 2014 yang dilakukan terhadap 2,5 juta orang autisme ditemukan gangguan medis dan psikiatris pada hampir semua orang autisme. Penelitian yang dilakukan Blider dan kawan-kawan juga mengaskan bahwa angka kematian orang yang didiagnosis autisme dengan komorbiditas meningkat hingga 3-10 kali lebih tinggi dibandingkan populasi umum. Angka komorbiditas pada anak autisme di Manado belum diketahui secara pasti karena survei mengenai banyaknya anak autisme sendiri pun tidak pernah dilakukan sampai saat ini. ${ }^{8,10-, 12}$

\section{METODE PENELITIAN}

Jenis penelitian ini ialah deskriptif kuantitatif untuk mengetahui gangguan atau gejala yang ada pada anak gangguan spektrum autisme menggunakan kuesioner.

Penelitian ini dilakukan selama bulan November 2015 sampai Januari 2016 di sekolah-sekolah autisme dan tempat terapi anak autisme yang ada di ManadoTomohon. Populasi yang diambil dalam 
penelitian ini yaitu semua anak autisme yang dideteksi autisme di SLB Khusus Autis Permata Hati, SLB Khusus Autis Hizkia, SLB AGCA Center Manado, SLB GMIM Nazareth Tuminting, SLB B/C Kristen Emmanuel, SLB A Bartemeus, SLB YPAC MANADO, SLB Tuna Grahita St. Anna, Autism Center Manado, Sentra Pendidikan Anak Berkebutuhan Khusus Amadeus yang berusia 3 sampai 17 tahun. Teknik pengambilan sampel yang digunakan adalah dengan cara purposive sampling dimana pengambilan sampel secara sengaja sesuai dengan persyaratan sampel yang diperlukan peneliti. Variabel dependen yaitu anak dengan gangguan spektrum autisme dan variabel independen yaitu komorbiditas.

\section{HASIL PENELITIAN}

Penelitian komorbiditas dilakukan terhadap anak gangguan spektrum autisme di SLB Khusus Autis Permata Hati, SLB Khusus Autis Hizkia, SLB AGCA Center Manado, SLB GMIM Nazareth Tuminting, SLB B/C Kristen Emmanuel, SLB A Bartemeus, SLB YPAC MANADO, SLB Tuna Grahita St. Anna, Autism Center Manado, Sentra Pendidikan Anak Berkebutuhan Khusus Amadeus pada bulan November 2015 sampai bulan Januari 2016. Dideteksi ada 64 anak dengan gangguan spektrum autisme melalui skrining awal. Total responden yang berpartisipasi dalam pengisian kuesioner mengenai komorbiditas gangguan spektrum autisme sebanyak 31 responden dari 33 kuesioner yang dikembalikan.

\section{Distribusi anak gangguan spektrum autisme berdasarkan usia}

Dari 31 anak gangguan spektrum autisme, 2 diantaranya berusia 6 tahun $(6,45 \%), 3$ orang berusia 7 tahun $(9,68 \%)$, 4 orang berusia 8 tahun $(12,9 \%), 3$ orang berusia 9 tahun $(9,68 \%), 3$ orang berusia 10 tahun $(9,68 \%), 2$ orang berusia 11 tahun $(6,45 \%), 2$ orang berusia 12 tahun $(6,45 \%)$, 2 orang berusia 13 tahun $(6,45 \%), 2$ orang berusia 14 tahun $(6,45 \%), 3$ orang berusia
15 tahun $(9,68 \%), 2$ orang berusia 16 tahun $(6,45 \%), 3$ orang berusia 17 tahun $(9,68 \%)$.

Tabel 1. Distribusi anak gangguan spektrum autisme berdasarkan usia

\begin{tabular}{ccc}
\hline Usia & \multicolumn{2}{c}{$\begin{array}{c}\text { Jumlah Anak Gangguan } \\
\text { Spektrum Autisme }\end{array}$} \\
\cline { 2 - 3 } & $\mathrm{N}$ & $\%$ \\
\hline 3 & 0 & 0 \\
4 & 0 & 0 \\
5 & 0 & 0 \\
6 & 2 & 6.45 \\
7 & 3 & 9.68 \\
8 & 4 & 12.9 \\
9 & 3 & 9.68 \\
10 & 3 & 9.68 \\
11 & 2 & 6.45 \\
12 & 2 & 6.45 \\
13 & 2 & 6.45 \\
14 & 2 & 6.45 \\
15 & 3 & 9.68 \\
16 & 2 & 6.45 \\
17 & 3 & 9.68 \\
Total & 31 & 100 \\
\hline
\end{tabular}

Distribusi anak gangguan spektrum autisme berdarkan jenis kelamin

Pada penelitian ini didapatkan 24 anak laki-laki $(77,4 \%)$ dan 7 anak perempuan $(22,6 \%)$ dari total 31 anak gangguan spektrum autisme.

Tabel 2. Distribusi anak gangguan spektrum autisme berdasarkan jenis kelamin

\begin{tabular}{|c|c|c|}
\hline \multirow[t]{2}{*}{$\begin{array}{l}\text { Jenis } \\
\text { Kelamin }\end{array}$} & \multicolumn{2}{|c|}{$\begin{array}{c}\text { Jumlah Anak Gangguan } \\
\text { Spektrum Autisme }\end{array}$} \\
\hline & $\mathrm{N}$ & $\%$ \\
\hline Laki-Laki & 24 & 77.4 \\
\hline Perempuan & 7 & 22.6 \\
\hline Total & 31 & 100 \\
\hline
\end{tabular}

Distribusi komorbiditas pada anak gangguan spektrum autisme berdasarkan usia

Dari 31 responden pada penelitian ini didapatkan 15 anak gangguan spektrum autisme $(48,4 \%)$ yang berusia 3-10 tahun dan 15 anak gangguan spektrum autisme $(48,4 \%)$ yang berusia 11-17 tahun mengalami komorbitas. 
Tabel 3. Distribusi komorbiditas pada anak gangguan spektrum autisme berdasarkan usia

\begin{tabular}{ccc}
\hline $\begin{array}{c}\text { Usia } \\
\text { (tahun) }\end{array}$ & $\begin{array}{c}\text { Anak Dengan } \\
\text { Komorbiditas } \\
\mathrm{N}\end{array}$ & $\begin{array}{c}\text { Anak Tanpa } \\
\text { Komorbiditas } \\
\mathrm{N}\end{array}$ \\
\hline $\begin{array}{c}\text { Younger } \\
(3-10)\end{array}$ & 15 & 0 \\
$\begin{array}{c}\text { Adolescence } \\
(11-17)\end{array}$ & 15 & 1 \\
Total & 30 & 1 \\
\hline
\end{tabular}

Distribusi banyaknya komorbiditas pada anak gangguan spektrum autisme

Dari 31 responden didapatkan hasil terbanyak 30 anak gangguan spektrum autisme $(96,77 \%)$ memiliki komorbiditas dan 1 anak gangguan spektrum autisme $(3,2 \%)$ tidak memiliki komorbiditas. Anak gangguan spektrum autisme yang memiliki 1 komorbiditas berjumlah 6 orang $(19,4 \%)$ dan yang memiliki lebih dari 1 komorbiditas berjumlah 24 orang $(77,4 \%)$.

Tabel 4. Distribusi banyaknya komorbiditas pada anak gangguan spektrum autisme

\begin{tabular}{ccc}
\hline Banyaknya & \multicolumn{2}{c}{$\begin{array}{c}\text { Anak Gangguan } \\
\text { Komorbiditas }\end{array}$} \\
\cline { 2 - 3 } & $\mathrm{N}$ & $\%$ \\
\hline Tidak ada & 1 & 3.2 \\
1 & 6 & 19.4 \\
$>1$ & 24 & 77.4 \\
& 30 & 100 \\
\hline
\end{tabular}

Distribusi komorbiditas pada anak gangguan spektrum autisme

Hasil pengamatan yang dilakukan pada 31 responden, didapatkan anak gangguan spektrum autisme lebih banyak megalami gangguan mental dan penyakit fisik secara bersamaan yaitu sebanyak 23 orang $(74,2 \%)$. Anak gangguan spektrum autisme dengan penyakit fisik yaitu sebanyak 16 orang $(19,4)$, sedangkan anak gangguan spektrum autisme dengan gangguan mental sebanyak 1 orang $(3,2 \%)$.

Komorbiditas yang paling sering muncul pada anak gangguan spektrum autisme adalah gangguan gastrointestinal yaitu sebanyak 23 orang $(74,2 \%)$. Anak gangguan spektrum autisme yang mengalami gangguan cemas menyeluruh sebanyak 7 orang $(22,6 \%), 9$ orang mengalami fobia spesifik (29\%), 6 orang mengalami gangguan obsesif kompulsif $(19,4 \%), 5$ orang mengalami depresif mayor $(12,9 \%), 8$ orang mengalami gangguan bipolar $(25,8 \%), 7$ orang mengalami GPPH $(22,6 \%), 22$ orang mengalami alergi $(71 \%)$, dan 4 orang mengalami epilepsi $(12,9 \%)$ (Tabel 6).

Tabel 5. Distribusi komorbiditas berdasarkan gangguan mental dan penyakit fisik pada anak gangguan spektrum autism

\begin{tabular}{lcc}
\hline Komorbiditas & \multicolumn{2}{c}{$\begin{array}{c}\text { Jumlah Anak } \\
\text { Gangguan Spektrum } \\
\text { Autisme }\end{array}$} \\
\cline { 2 - 3 } & $\mathrm{N}$ & $\%$ \\
\hline Gangguan & & 3,2 \\
Mental & 1 & 19,4 \\
Penyakit Fisik & 6 & \\
Gangguan & & 74,2 \\
Mental \& & & 3,2 \\
Penyakit Fisik & 23 & 100 \\
Tidak ada & 1 & \\
Total & 31 & \\
\hline
\end{tabular}

Tabel 6. Distribusi komorbiditas berdasarkan klasifikasi pada anak gangguan spektrum autism

\begin{tabular}{lcc}
\hline \multirow{2}{*}{ Komorbiditas } & \multicolumn{2}{c}{$\begin{array}{c}\text { Anak Gangguan } \\
\text { Spektrum Autisme }\end{array}$} \\
\cline { 2 - 3 } & $\mathrm{N}$ & $\%$ \\
\hline Cemas & 7 & 22,6 \\
Menyeluruh & 7 & 29 \\
Fobia Spesifik & 9 & \\
Obsesif & & 19,4 \\
Kompulsif & 6 & 16,1 \\
Depresif Mayor & 5 & 25,8 \\
Bipolar & 8 & 22,6 \\
GPPH & 7 & 71 \\
Alergi & 22 & 74,2 \\
Gangguan & & 12.9 \\
gastrointestinal & 23 & \\
Epilepsi & 4 &
\end{tabular}

\section{BAHASAN}

Berdarkan hasil penelitian yang dilakukan pada 31 responden anak gangguan spektrum autisme di SLB Khusus Autis Permata Hati, SLB Khusus Autis 
Hizkia, SLB AGCA Center Manado, SLB GMIM Nazareth Tuminting, SLB B/C Kristen Emmanuel, SLB A Bartemeus, SLB YPAC MANADO, SLB Tuna Grahita St. Anna, Autism Center Manado, Sentra Pendidikan Anak Berkebutuhan Khusus Amadeus, diperoleh 1 orang $(3,2 \%)$ tidak memiliki komorbiditas, $6(19,4 \%)$ orang mempunyai 1 komorbiditas dan 24 orang $(77,4 \%)$ mempunyai lebih dari 1 komorbiditas. Hasil penelitian ini berbeda dengan penelitian yang dilakukan di Mental Health Center di Maastricht, Belanda tahun 2012 dan dari 40 anak didapatkan 23 anak gangguan spektrum autisme memiliki 1 komorbiditas $(57,5 \%)$. Hal ini disebabkan karena pada penelitian ini tidak hanya memasukan komorbiditas gangguan mental tetapi juga mengikut sertakan gangguan fisik seperti gangguan gastrointestinal, alergi dan epilepsi yang mana merupakan komorbiditas yang paling sering menyertai anak autisme pada penelitian ini. Saat ini tidak ditemukan peneletian yang membahas secara bersamaan gangguan mental dan gangguan fisik pada anak gangguan spektrum autisme. ${ }^{13}$

Selain itu pada penelitian ini didapati bahwa komorbiditas yang paling sering menyertai anak dengan gangguan spektrum autisme adalah gangguan fisik yaitu gangguan gastrointestinal sebanyak 23 orang $(74,2 \%)$ dari 31 responden. Hasil ini tidak berbeda jauh dengan angka kejadian gangguan gastrointestinal terhadap responden gangguan spektrum autisme yang dibagi dalam case subjects yang berjumlah 94 orang $(77,2 \%)$ mengalami gangguan gastrointestinal dari 121 orang dan control subjects 175 orang $(72,2 \%)$ dari 242 orang. ${ }^{14}$

Hasil penelitian ini juga menunjukan bahwa gangguan mental yang tersering timbul pada anak gangguan spektrum autisme adalah fobia spesifik sebanyak 9 orang $(29 \%)$ dari total 31 anak dengan gangguan spektrum autisme. Hasil penelitian ini juga sedikit berbeda dengan penelitian sebelumnya yang dilakukan di Maastricht, Belanda tahun 2012, di mana komorbiditas yang paling sering menyertai anak gangguan spektrum autisme adalah GPPH sebanyak 9 orang $(22.5 \%)$ dari 40 orang. Tetapi hasil penelitian ini hampir sama dengan penelitian yang dilakukan terhadap anak-anak yang terdiagnosis gangguan spektrum autisme di Boston dan Salt Lake City pada tahun 2006, komorbiditas yang paling sering menyertai anak gangguan spektrum autisme adalah fobia spesifik sebanyak 43 orang $(44,3 \%)$ dari 109 orang. ${ }^{7,13}$

Hasil penelitian ini tidak menunjukkan bahwa anak gangguan spektrum autisme yang berusia 3-10 tahun lebih sering terkena komorbiditas. Penelitian ini menunjukan bahwa anak autisme yang berusia 3-10 tahun dan anak autisme yang berusia 11-17 tahun (remaja) memiliki insidensi yang sama terkena komorbiditas yaitu masing-masing sebanyak 15 orang (48,4\%). Dalam hal ini, dibutuhkan sampel yang lebih banyak lagi untuk meunjukkan perbedaan hasil yang lebih signifikan. ${ }^{1}$

\section{SIMPULAN}

Berdasarkan hasil penelitian yang dilakukan dapat disimpulkan bahwa sebagian besar anak gangguan spektrum autisme menderita komorbiditas, umumnya lebih dari 1 komorbiditas, tersering ialah penyakit fisik berupa gangguan gastrointestinal dan gangguan mental berupa fobia spesifik.

\section{DAFTAR PUSTAKA}

1. Fred R, Ami K, Robert TS, et al. Pervasive Developmental Disorders. Sadock B. J, Sadock V. A, Ruiz P, editors. Kaplan \& Sadock's Comprehensive Textbook of Psychiatry. $9^{\text {th }}$ ed. Philadelphia: Lippincot Williams \& Wilkins. p. 3541-9

2. National Institutes of Mental Health. Autism Spectrum Disorders.Rockville: Departement of Health \& Human Services USA, 2008;1-35.

3. Ma'ruf E, Prasetyo R, Rini HL. Gambaran faktor pre natal sebagai penyebab autis di Sekolah Anak Khusus Kembang Mekar Desa 
Kepanjen Kecamatan Jombang Kabupaten Jombang tahun 2013. Jurnal Metabolisme.2013; Volume $3: 2$.

4. Setiawan F. Pola Penanganan Anak Autis di Yayasan Sayap Ibu. Skripsi, Yogyakarta, Fakultas Dakwah Universitas Islam Negeri Sunan Kalijaga Yogyakarta, 2010.

5. Ratajczak HV. Theoretical Aspects of Autism: Causes-A Review. Journal of Immunotoxicology. 2011;8:68

6. Johny LM, Marie SN. Comorbid Psychopathology with autism spectrum disorder in children: An overview. Research in Developmental Disabilities. 2007. 28;341-52

7. Leyver OT, Folstein SE, Bacalaman S, et al. Comorbid Psychiatric Disorders in Children with Autism: Interview Development and Rates of Disorders. J Autism Dev Disord.2006;36:341-47

8. Treating Autism, ESPA Research, Autism Treatment Plus. Medical Comorbidities in Autism Spectrum Disorders $\left(2^{\text {nd }}\right.$ ed). Treating Autism Publications, 2014

9. Elaine YH. Gastrointestinal Issues in Autism Spectrum Disease Disorder. Harvard Review of Psychiatry.2014;22:104-5

10.Croen LA, Zerbo O, Qian Y, et al. Psychiatric and Medical Conditions Among Adults with ASD. IMFAR paper presentation [accesed 2015 May 15). Available from: https://imfar.confex.com/imfar/2014/ webprogram/Paper17783.html

11.Bilder D, Botts EL, Smith KR, et al. Excess Mortality and Causes of Death in Autism Spectrum Disorders: A Follow up of the 1980s Utah/UCLA Autism Epidemiologic Study. Journal of Autism and Developmental Disorders. 2012;25:1-9

Gurney JG, McPheeters ML, and Davis MM. Parental report of health conditions and health care use among children with and without autism: National Survey of Children's Health. Arch Pediatric Adolescene Med. 2006;160:825-30.

12.Francisca J, Steensel A, Susan MB, et al. Psychiatric Comorbidity in Children with Autism Spectrum Disorders: A Comparasion with Children with ADHD. J Child Fam Stud.2013;22:372

13.Samar HI, Robert GV. Slavica KK, et al. Incidence of Gastrointestinal Symptoms in Children with Autism: A Population-Based Study. American Academy of Pediatrics. 2009;124:682

14. Nirbhay NS, Robert GW, Alan SWW, et al. A Mindfulness- Based Treatment of Obsessive-Compulsive Disorder. The Mindfulness Research Group. 2012:1

15.Phillip G, Kent CW, Evon BL, et al. Gastrointestinal Dysfucntion in Autism: Parental Report, Clinical Evaluation \& Associated Factors. National Institutes of Health. 2012;101-8.

16.Golam H, Monjura A. The Relation of Socio-economic Factors with Autism among Children: A study in an Urbam Area of Bangladesh. Journal of Pioneering Medical Sciences. 2014;4:11-3. 